Research Article

\title{
Frequency-Reconfigurable Dipole Antenna Using Liquid-Metal Pixels
}

\author{
Kent J. Sarabia $(D$, Sasha S. Yamada, Matthew R. Moorefield, Anthony W. Combs, \\ Aaron T. Ohta, and Wayne A. Shiroma
}

Department of Electrical Engineering, University of Hawaii at Manoa, 2540 Dole St., Honolulu, HI 96822, USA

Correspondence should be addressed to Kent J. Sarabia; kjsara@hawaii.edu

Received 18 October 2017; Accepted 16 January 2018; Published 14 March 2018

Academic Editor: Giorgio Montisci

Copyright ( $) 2018$ Kent J. Sarabia et al. This is an open access article distributed under the Creative Commons Attribution License, which permits unrestricted use, distribution, and reproduction in any medium, provided the original work is properly cited.

\begin{abstract}
A frequency-tunable half-wavelength dipole antenna is realized using an array of electrically actuated liquid-metal pixels. The liquid-metal pixelated dipole antenna demonstrates frequency reconfigurability by switching between resonances at $2.51 \mathrm{GHz}$, $2.12 \mathrm{GHz}, 1.85 \mathrm{GHz}$, and $1.68 \mathrm{GHz}$.
\end{abstract}

\section{Introduction}

Reconfigurable antennas offer an adaptive solution in a dynamic communication environment, demonstrating the ability to change radiation pattern, polarization, and operational frequency $[1,2]$. Although reconfigurability is typically achieved using PIN diodes [3], varactors [4], or MEMS switches [5], liquid metal has also recently been shown to implement reconfigurable antennas.

Recent demonstrations in liquid-metal reconfigurable antennas include monopole [6,7], dipole [8], planar inverted F [9], Yagi-Uda [10-12], patch [13, 14], and slot [15] antennas. Reconfigurability is achieved either by altering the physical dimensions of the radiating element with liquid metal or by configuring an associated liquid-metal parasitic element.

This paper achieves frequency reconfiguration using liquid metal in the form of square pixels. Pixelated antennas have been demonstrated before [16-19], but this is the first paper to implement antenna pixelation using liquid metal. To turn on a pixel, a discrete amount of liquid metal is electrically actuated from a reservoir buried below the antenna. To turn off a pixel, the liquid metal retreats to the buried reservoir [20].

\section{Design}

2.1. Liquid-Metal Pixelated Dipole. The resonant frequency of a half-wavelength dipole antenna depends on the electrical length of the dipole arms. Using liquid-metal pixels to adjust the dipole length results in discrete changes in the antenna's operating frequency. Figure 1 illustrates the concept. The liquid-metal pixelated antenna is based on the dimensions of a $64 \mathrm{~mm}$ long baseline planar copper dipole on a $0.787 \mathrm{~mm}$ thick Duroid 5880 substrate, shown in Figure 1(a). The liquid-metal pixelated antenna shown in Figure 1(b) replaces a section of both dipole arms with a $1 \times 4$ pixel array. The walls of the pixel array are made of polyimide. The top side of the array is covered in polystyrene, and the bottom side of the array is covered in polydimethylsiloxane (PDMS). Adjacent pixels on the top side are interconnected with stainless-steel connectors embedded between the pixel walls. The pixel array connects to the copper section of the antenna through a soldered stainless-steel wire. This is necessary as gallium-based liquid metals such as Galinstan [21] used in this antenna amalgamates with copper, compromising actuation. Although Galinstan reacts with some materials, it has no known adverse effects on the human 


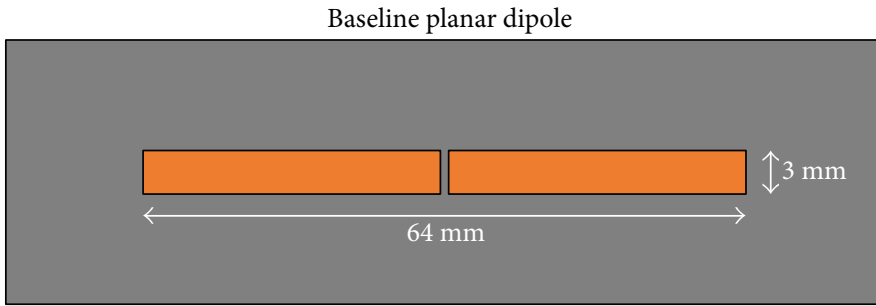

Substrate

$\square$ Copper

(a)

Liquid-metal pixelated dipole

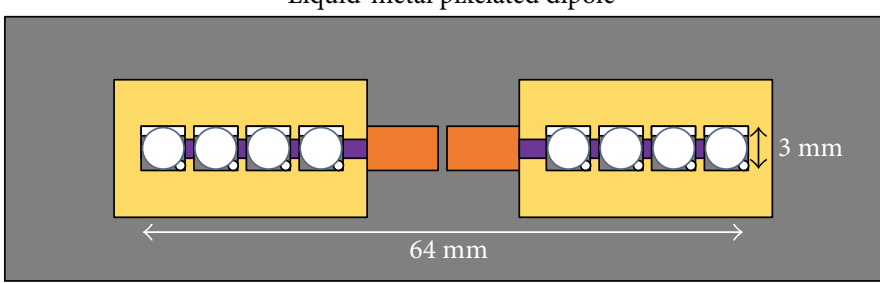

$\square$ Polyimide

$\square$ Substrate

$\square$ Copper

$\square$ Stainless steel

(b)
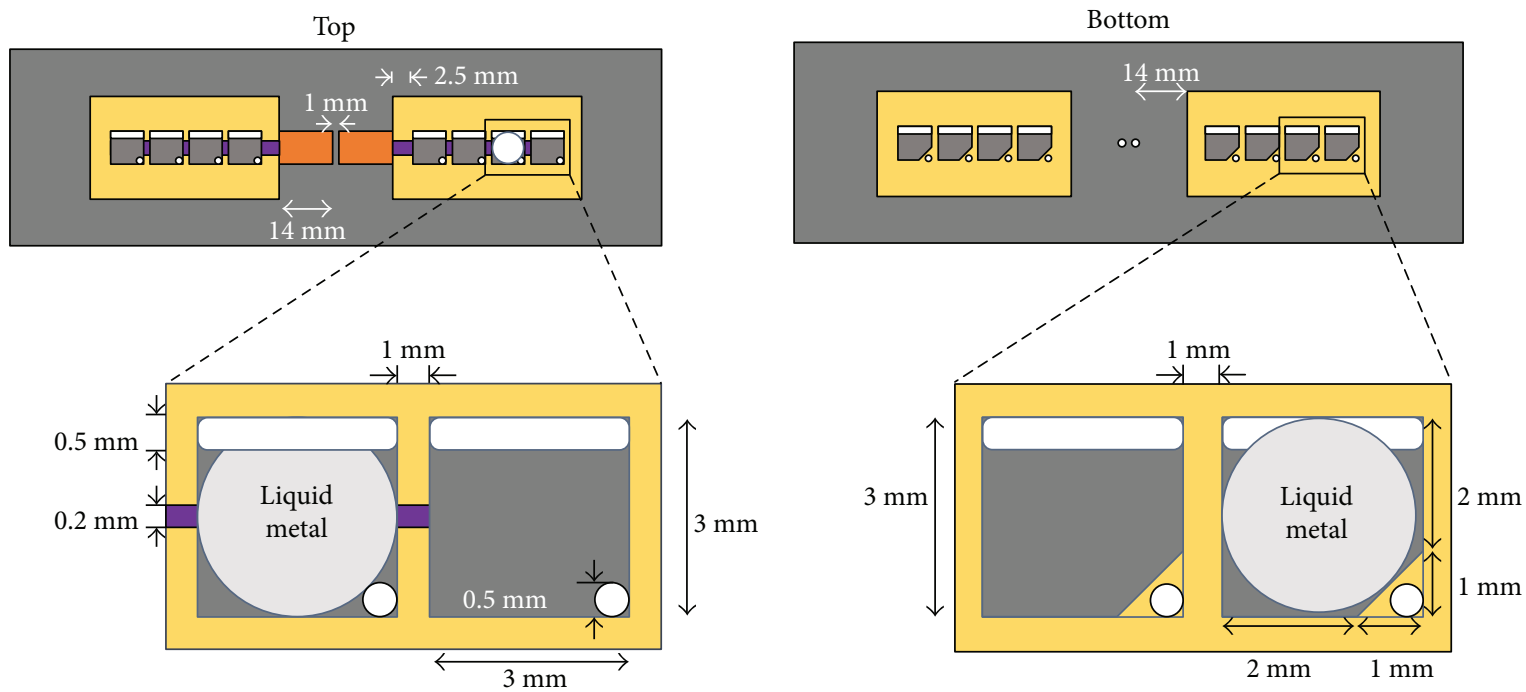

$\square$ Polyimide

$\square$ Copper

Stainless steel

$\square$ Polyimide

Substrate

(c)

(d)

Side

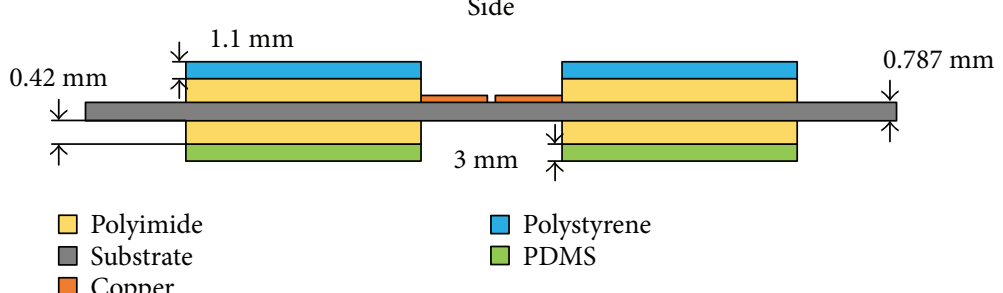

(e)

FIGURE 1: (a) Baseline planar dipole antenna to compare to liquid-metal pixelated equivalent. (b) Liquid-metal pixelated dipole prototype filled with liquid metal. (c) Top side with zoom-in of pixels. The left pixel is in the "on" state, with liquid metal present and interfacing with stainless steel placed within the walls between pixels. (d) Bottom side with zoom-in of pixels. The right pixel is in the "off" state. (e) Side view. 

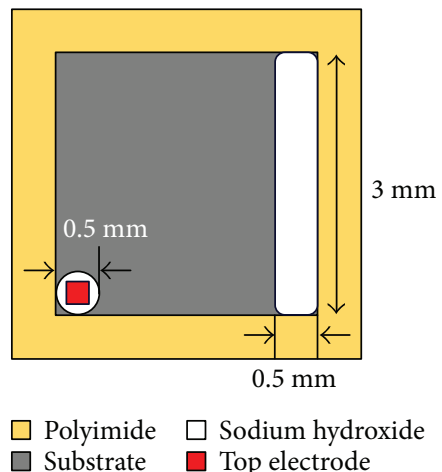

(a)
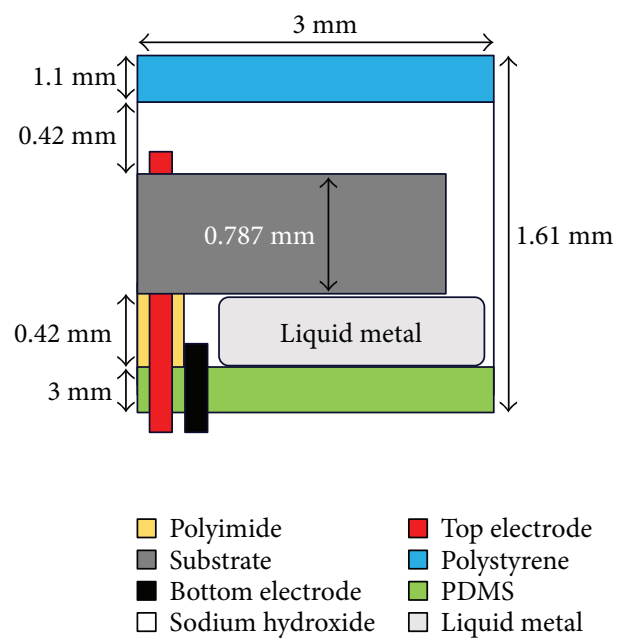

(c)

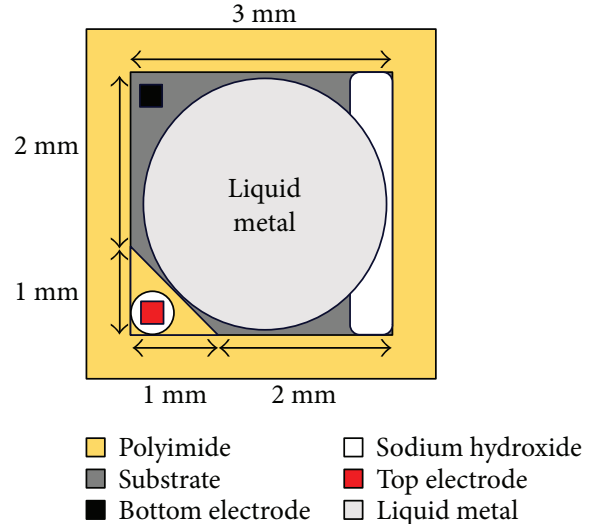

(b)
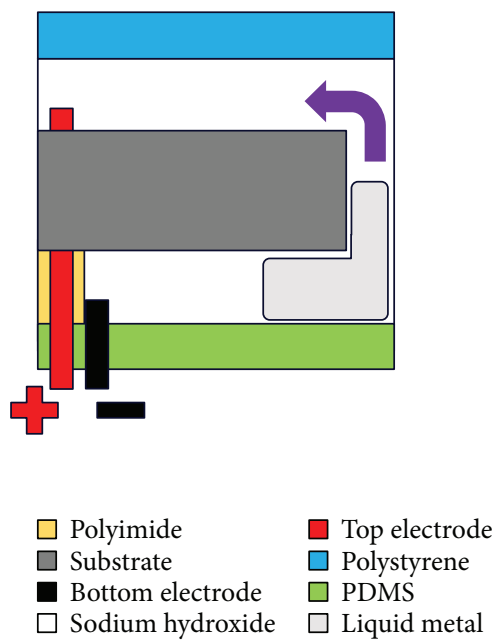

(d)

Figure 2: Layout of pixel in the "off" state. (a) Top side of pixel. (b) Bottom side with liquid metal present. (c) Side view with liquid metal residing on the bottom side. (d) Application of voltage on the electrodes moves the liquid metal from the bottom side to the top side.

body [21]. The interface between the copper and pixel array is covered in a watertight polymer, which is not shown in Figure 1.

2.2. Liquid-Metal Pixel. A layout of a pixel is shown in Figure 2. Liquid metal moves between the top and bottom reservoirs by applying a voltage on the electrodes. Both electrodes are fed through the bottom reservoir, which is covered with a layer of PDMS. The electrodes are electrically isolated from each other on the bottom side of the pixel. A pixel is considered "on" when the liquid metal is actuated to the top-side reservoir of the antenna. The pixel is turned "off" when the liquid metal is actuated to the bottom-side reservoir.

2.3. Liquid-Metal Actuation Mechanism. Liquid metal is actuated by manipulating its surface tension using continuous electrowetting (CEW) [22]. Liquid metal is immersed in a $1 \mathrm{M}$ solution of sodium hydroxide $(\mathrm{NaOH})$, forming an electrical double layer (EDL) at the metal- $\mathrm{NaOH}$ interface. A voltage acting on the EDL creates a surface tension imbalance on the liquid metal. This results in a pressure differential, actuating the liquid metal. Figure 3 demonstrates actuation in an early $4 \mathrm{~mm} \times 4 \mathrm{~mm}$ liquid-metal pixel prototype. A $1.2 \mathrm{~V}$ square wave with a $+1 \mathrm{~V}$ DC offset is applied to the electrodes to actuate the liquid metal from a reservoir buried below. The liquid metal is then actuated back to the reservoir by swapping the applied voltage polarities on the electrodes.

The pixels built for the liquid-metal pixelated dipole utilize a $3 \mathrm{~mm} \times 3 \mathrm{~mm}$ design. The actuation voltage for this design is a $30 \mathrm{~Hz} 4 \mathrm{~V}$ square wave with a $+1 \mathrm{~V}$ DC offset, which induces a larger actuation force than the $1.2 \mathrm{~V}$ actuation voltage used in the $4 \mathrm{~mm} \times 4 \mathrm{~mm}$ prototype pixel. The larger force acting on a smaller body of liquid metal within the pixel significantly increases actuation speeds, being able to switch the pixel between the on and off states within 0.03 to 0.09 seconds.

\section{Experimental Results}

The antenna is tested by incrementally turning on one pixel on each dipole arm and then measuring the resulting resonance frequency and radiation pattern. The measured resonance frequencies agree with simulated values obtained from an ANSYS HFSS model (Table 1). 


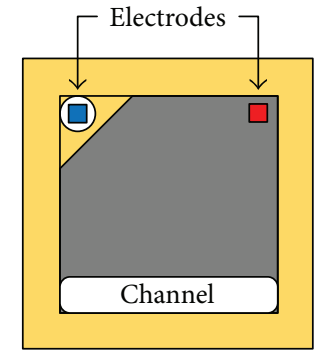

(a)

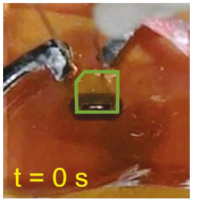

(c)

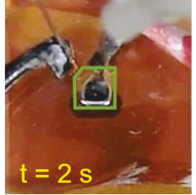

(d)

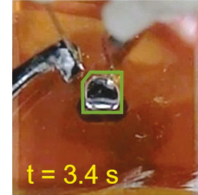

(e)

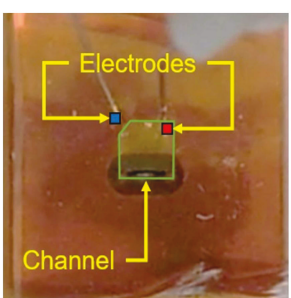

(b)

Figure 3: (a) Layout of the prototype pixel bottom side with an actuation circuit. (b) Fabricated pixel with an outlined pixel and electrodes. Stainless-steel syringes (not shown) are used to puncture the PDMS. (c) Application of $1.2 \mathrm{~V}$ to actuate liquid metal from a reservoir buried below. (d) Liquid metal actuating. (e) Completion of liquid-metal actuation. (f) Swapping voltage applied to electrodes. (g) Liquid metal retreats to the reservoir below. (h) Completion of liquid-metal actuation.

TABLE 1: Measured versus simulated resonance frequencies.

\begin{tabular}{lcccc}
\hline "On" pixels (per arm) & 1 & 2 & 3 & 4 \\
\hline Measured $(\mathrm{GHz})$ & 2.51 & 2.12 & 1.85 & 1.68 \\
Simulated $(\mathrm{GHz})$ & 2.43 & 2.08 & 1.88 & 1.78 \\
\hline
\end{tabular}

TABLE 2: Baseline planar copper dipole versus pixelated dipole.

\begin{tabular}{lcc}
\hline Parameter & Bandwidth (\%) & Efficiency $(\%)$ \\
\hline Planar copper & 12.1 & 79.5 \\
4 pixels & 17.9 & 72.6 \\
3 pixels & 21.6 & 75.4 \\
2 pixels & 17.5 & 72.6 \\
1 pixel & 13.6 & 70.2 \\
\hline
\end{tabular}

As expected, lengthening the dipole by adding liquidmetal pixels on each arm decreases the resonant frequency of the antenna. As the antenna becomes longer, the incremental frequency shift decreases as the inverse square of the antenna length, as expected from the derivative of $f=v / \lambda=v / 2 l$ :

$$
\frac{d f}{d l}=-\frac{v}{2 l^{2}}
$$

where $f$ is the frequency, $l$ is the antenna length, and $v$ is the propagation velocity.

The frequency bandwidth and antenna efficiency of the pixelated dipole antenna are compared to those of a planar copper dipole antenna (Table 2). The performance of the pixelated dipole does not deviate significantly from that of the baseline planar copper dipole.

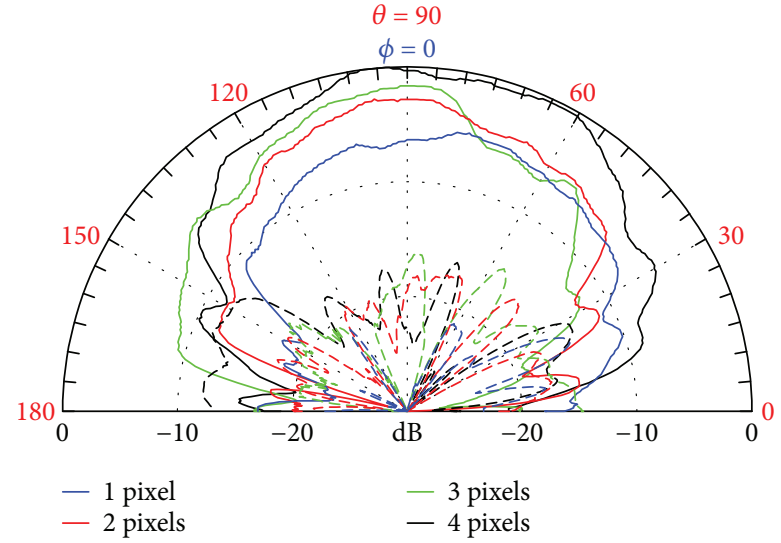

(a)

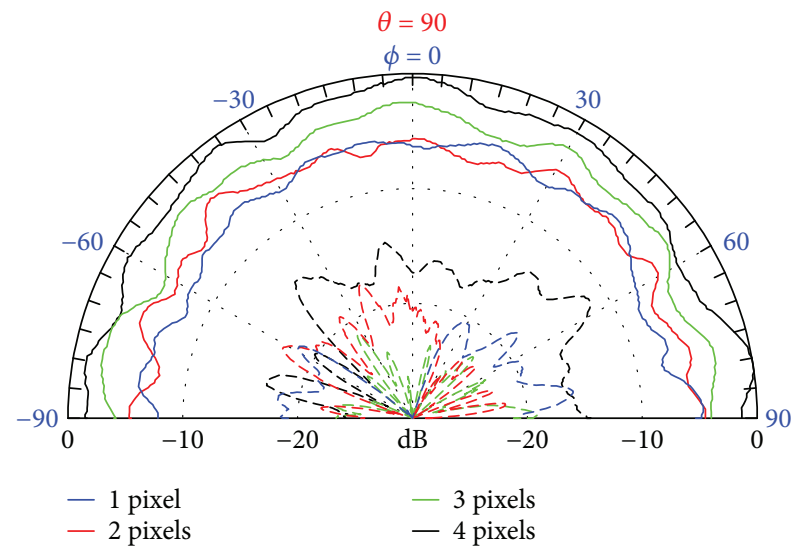

(b)

FIgURE 4: Measured copolarized (solid) and cross-polarized (dashed) radiation patterns in the (a) E-plane and (b) H-plane. 


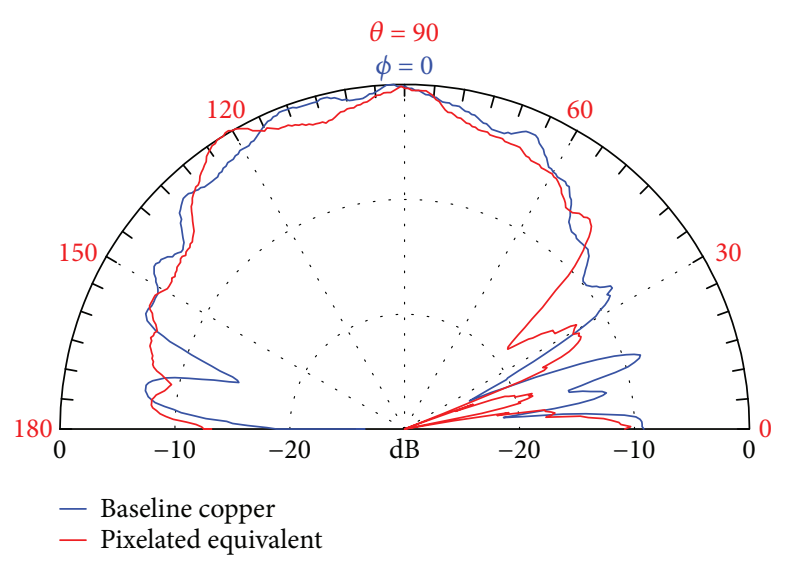

(a)

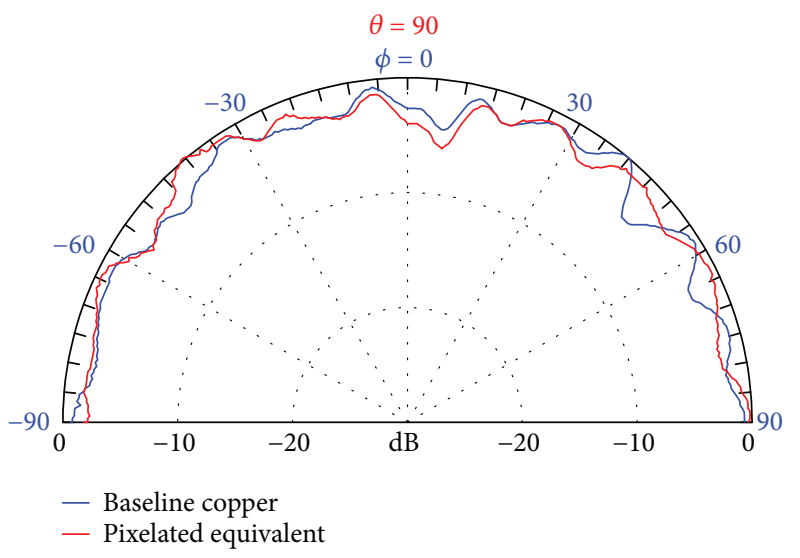

(b)

Figure 5: Comparison of baseline copper dipole and pixelated copper equivalent: (a) E-plane and (b) H-plane.

The measured radiation patterns are that of a typical dipole antenna, with nulls at $\theta=0^{\circ}$ and $180^{\circ}$ in the E-plane and an omnidirectional pattern in the $\mathrm{H}$-plane (Figure 4). The variation in peak gain between the 1- and 4-pixel-perarm cases is approximately $\pm 3 \mathrm{~dB}$. The cross-polarization ratio is between 10 and $20 \mathrm{~dB}$.

The effect of pixelating the baseline dipole was also investigated. Figure 5 compares the measured radiation pattern of the baseline planar copper dipole to that of a pixelated copper equivalent. Both antennas are tested at $2.1 \mathrm{GHz}$. This figure shows that pixelation of the dipole antenna presented in this paper has negligible effects on the radiation pattern at the resonant frequency.

\section{Conclusion}

This paper demonstrates the first implementation of a pixelated antenna using liquid metal. Pixels actuate liquid metal with a $4 \mathrm{~V}$ signal to increase the length of a dipole antenna. This allows a pixelated dipole antenna to resonate at $2.51 \mathrm{GHz}, 2.12 \mathrm{GHz}, 1.85 \mathrm{GHz}$, and $1.68 \mathrm{GHz}$. It has also been found that pixelation of the dipole antenna presented in this paper has negligible effects on the radiation pattern at the resonant frequency.

\section{Conflicts of Interest}

The authors declare that they have no conflicts of interest.

\section{Acknowledgments}

This work is supported by the Defense Advanced Research Projects Agency under Grant W31P4Q-16-1-0005.

\section{References}

[1] C. G. Christodoulou, Y. Tawk, S. A. Lane, and S. R. Erwin, "Reconfigurable antennas for wireless and space applications," Proceedings of the IEEE, vol. 100, no. 7, pp. 2250-2261, 2012.

[2] J. Costantine, Y. Tawk, S. E. Barbin, and C. G. Christodoulou, "Reconfigurable antennas: design and applications," Proceedings of the IEEE, vol. 103, no. 3, pp. 424-437, 2015.

[3] S. Nikolaou, R. Bairavasubramanian, C. Lugo et al., "Pattern and frequency reconfigurable annular slot antenna using PIN diodes," IEEE Transactions on Antennas and Propagation, vol. 54, no. 2, pp. 439-448, 2006.

[4] N. Behdad and K. Sarabandi, "A varactor-tuned dual-band slot antenna," IEEE Transactions on Antennas and Propagation, vol. 54, no. 2, pp. 401-408, 2006.

[5] E. Erdil, K. Topalli, M. Unlu, O. A. Civi, and T. Akin, "Frequency tunable microstrip patch antenna using RF MEMS technology," IEEE Transactions on Antennas and Propagation, vol. 55, no. 4, pp. 1193-1196, 2007.

[6] A. M. Morishita, C. K. Y. Kitamura, A. T. Ohta, and W. A. Shiroma, "Two-octave tunable liquid-metal monopole antenna," Electronics Letters, vol. 50, no. 1, pp. 19-20, 2014.

[7] M. Wang, M. R. Khan, C. Trlica, M. D. Dickey, and J. J. Adams, "Pump-free feedback control of a frequency reconfigurable liquid metal monopole," in 2015 IEEE International Symposium on Antennas and Propagation \& USNC/URSI National Radio Science Meeting, pp. 2223-2224, Vancouver, BC, Canada, 2015.

[8] J.-H. So, J. Thelen, A. Qusba, G. J. Hayes, G. Lazzi, and M. D. Dickey, "Reversibly deformable and mechanically tunable fluidic antennas," Advanced Functional Materials, vol. 19, no. 22, pp. 3632-3637, 2009.

[9] A. Ha and K. Kim, "Frequency tunable liquid metal planar inverted-F antenna," Electronics Letters, vol. 52, no. 2, pp. 100-102, 2016.

[10] C. K. Y. Kitamura, A. M. Morishita, T. F. Chun, W. G. Tonaki, A. T. Ohta, and W. A. Shiroma, "A liquid-metal reconfigurable Yagi-Uda monopole array," in 2013 IEEE MTT-S International Microwave Symposium Digest (MTT), pp. 1-3, Seattle, WA, USA, June 2013.

[11] D. Rodrigo, L. Jofre, and B. A. Cetiner, "Circular beamsteering reconfigurable antenna with liquid metal parasitics," IEEE Transactions on Antennas and Propagation, vol. 60, no. 4, pp. 1796-1802, 2012.

[12] A. M. Morishita, C. K. Y. Kitamura, A. T. Ohta, and W. A. Shiroma, "A liquid-metal monopole array with tunable frequency, gain, and beam steering," IEEE Antennas and Wireless Propagation Letters, vol. 12, pp. 1388-1391, 2013.

[13] M. R. Moorefield, R. C. Gough, A. M. Morishita, J. H. Dang, A. T. Ohta, and W. A. Shiroma, "Frequency-tunable patch antenna with liquid-metal-actuated loading slot," Electronics Letters, vol. 52, no. 7, pp. 498-500, 2016. 
[14] M. Kelley, C. Koo, H. Mcquilken et al., "Frequency reconfigurable patch antenna using liquid metal as switching mechanism," Electronics Letters, vol. 49, no. 22, pp. 1370$1371,2013$.

[15] R. C. Gough, J. H. Dang, A. M. Morishita, A. T. Ohta, and W. A. Shiroma, "Frequency-tunable slot antenna using continuous electrowetting of liquid metal," in 2014 IEEE MTT-S International Microwave Symposium (IMS2014), pp. 1-3, Tampa, FL, USA, June 2014.

[16] D. Rodrigo, B. A. Cetiner, and L. Jofre, "Frequency, radiation pattern and polarization reconfigurable antenna using a parasitic pixel layer," IEEE Transactions on Antennas and Propagation, vol. 62, no. 6, pp. 3422-3427, 2014.

[17] D. Rodrigo and L. Jofre, "Frequency and radiation pattern reconfigurability of a multi-size pixel antenna," IEEE Transactions on Antennas and Propagation, vol. 60, no. 5, pp. 22192225, 2012.

[18] C. G. Christodoulou, L. F. Feldner, V. Zachou, and D. Anagnostou, "Planar reconfigurable antennas," in 2006 First European Conference on Antennas and Propagation, pp. 1-7, Nice, France, November 2006.

[19] A. G. Besoli and F. de Flaviis, "A multifunctional reconfigurable pixeled antenna using MEMS technology on printed circuit board," IEEE Transactions on Antennas and Propagation, vol. 59, no. 12, pp. 4413-4424, 2011.

[20] K. J. Sarabia, S. S. Yamada, R. C. Gough et al., "Out-of-plane continuous electrowetting actuation of liquid metal," Electronics Letters, vol. 53, no. 25, pp. 1635-1636, 2017.

[21] Geratherm Medical AG, "Galinstan safety data sheet [online]," August 2016, http://www.rgmd.com/msds/msds.pdf.

[22] J. Lee and C.-J. Kim, "Surface-tension-driven microactuation based on continuous electrowetting," Journal of Microelectromechanical Systems, vol. 9, no. 2, pp. 171-180, 2000. 


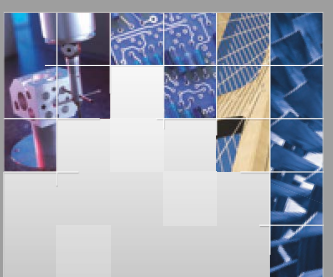

\section{Enfincering}
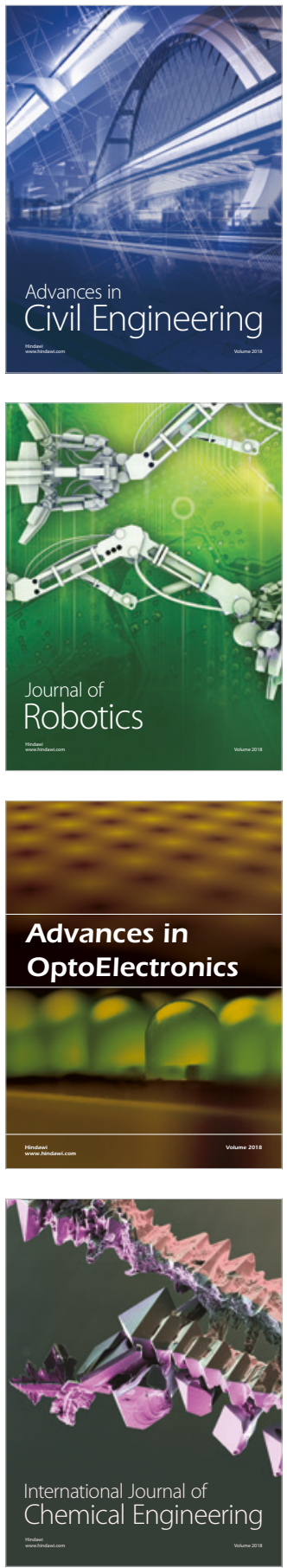

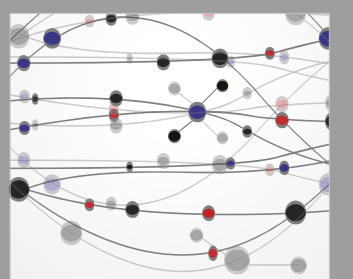

\section{Rotating \\ Machinery}

The Scientific World Journal

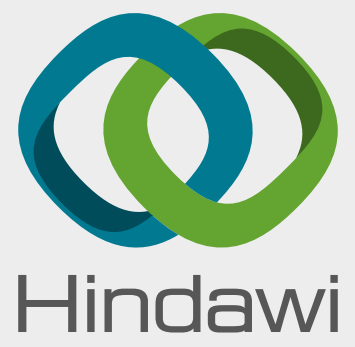

Submit your manuscripts at

www.hindawi.com
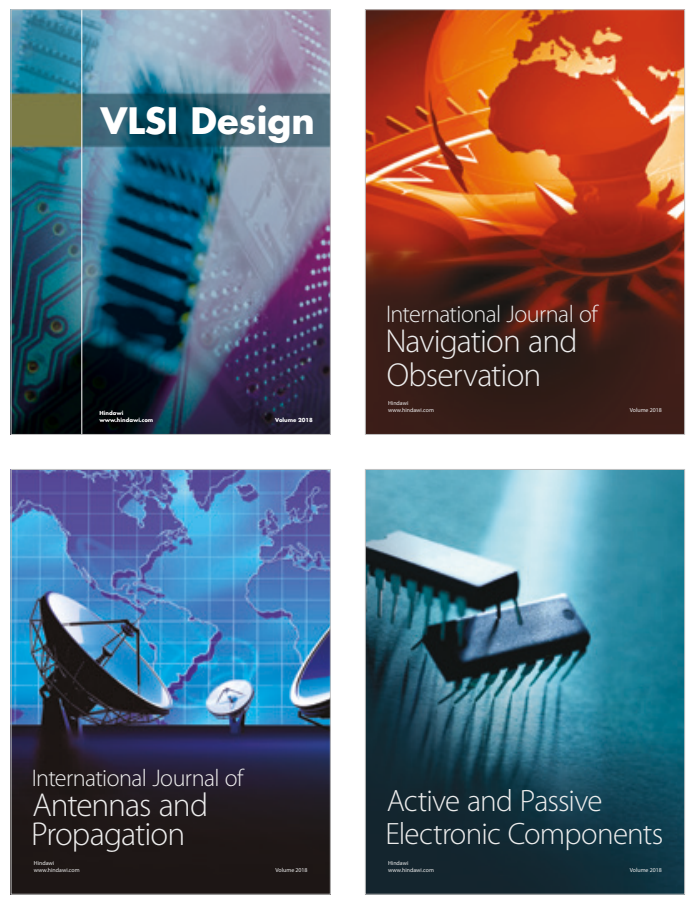
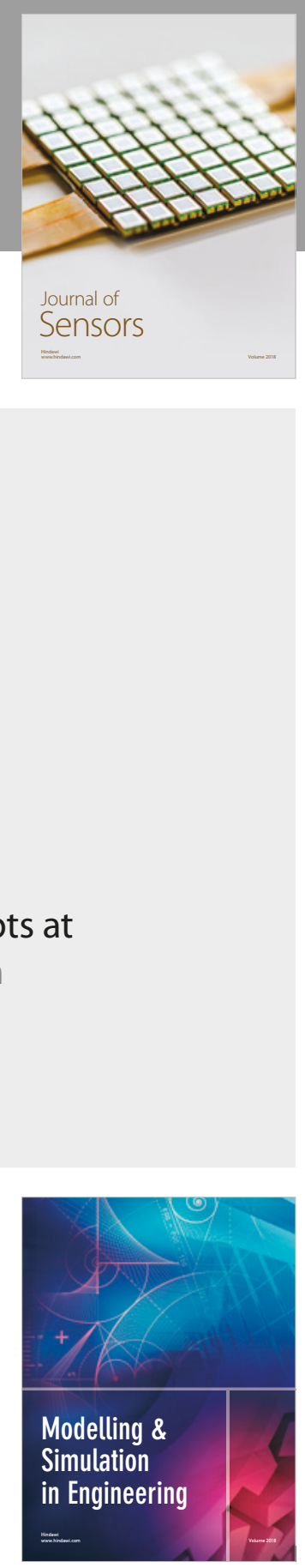

\section{Advances \\ Multimedia}
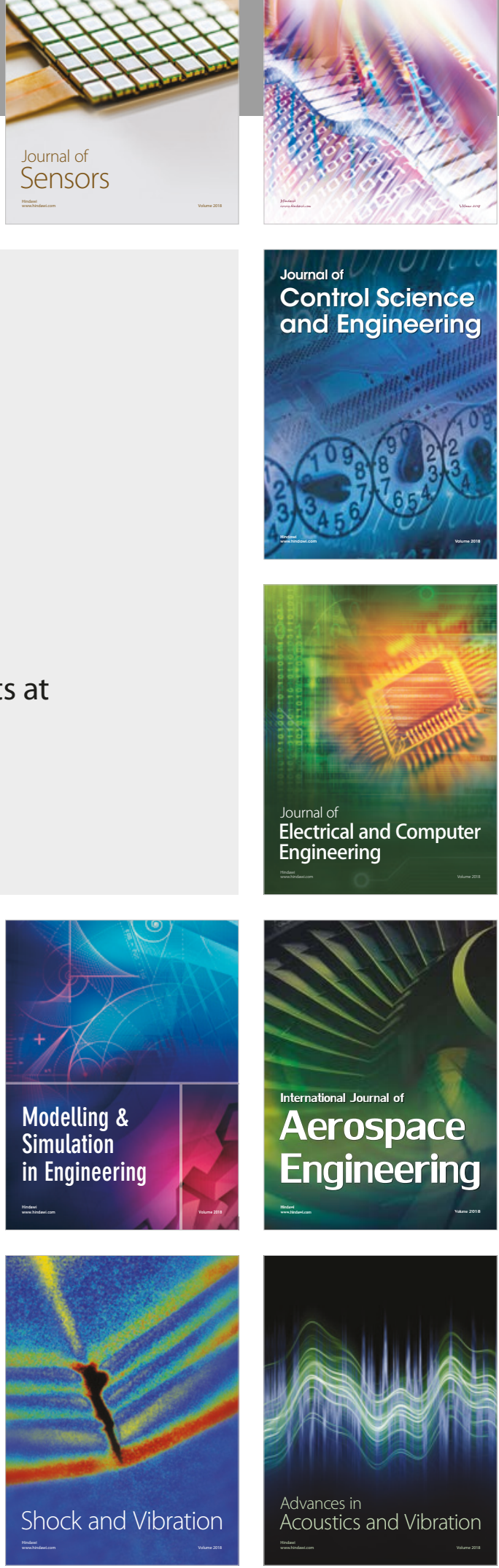